\title{
Comentario
}

\section{Estrategias para relacionarse con la Descripción y el Acceso a los Recursos}

a Descripción y Acceso a los Recursos está caracterizando
la nueva forma de concebir la práctica de la catalogación así como la de estar al tanto de lo que se dice respecto al juicio del catalogador que se apoya en lineamientos más que en el seguimiento de reglas. Para muchos bibliotecarios el cambio está resultando complicado y se resisten tanto a él que no quieren ver sus ventajas por el simple hecho de que éste pueda arruinar todo el trabajo anterior. Para otros, el nuevo estándar de descripción ha sido una oportunidad para sacar a flote y del témpano de hielo en el que se encontraba la práctica de la catalogación. Lo cierto es que, una vez iniciado este proceso, no habrá nada que lo detenga.

Hoy podemos decir con certeza que hay una vasta literatura especializada sobre los lineamientos para la Descripción y el Acceso a los Recursos (RDA por sus siglas en inglés), la cual abarca desde los proyectos en los cuales se argumentaba el deseo por contar con un nuevo código de catalogación, hasta los estudios de caso sobre la viabilidad de éste; desde el diseño de innovación en las bases de datos hasta la reorganización de los servicios técnicos de la biblioteca; desde la evolución, adaptación y cambio del formato MARC21 hasta el planteamiento de XML y el futuro de la catalogación descriptiva.

La historia del nuevo estándar de descripción es corta, pero ha evolucionado vertiginosamente desde el momento en que se liberó; es decir, desde el 2010, fecha declarada como el "Año de la Catalogación”. Sin embargo, los lineamientos para la Descripción y Acceso requieren de un entendimiento que va más allá de su interpretación. Esto es, necesitan que la mayoría de 
las bases de datos estén relacionadas entre sí para que se cumplan sus intenciones de colocar los "datos en la Web" y así otorgar validez a sus objetivos de responsabilidad con los usuarios, con el costo-eficiencia, la flexibilidad y la continuidad.

A partir del 2012 cualquier biblioteca, sin importar el tamaño, se ha interesado por introducir este estándar y preparar a su equipo de trabajo en actividades encauzadas a familiarizarse con el lenguaje de RDA, sus conceptos subyacentes y aquellos otros que quedan delimitados por el modelo conceptual de los requerimientos funcionales. También estos equipos de trabajo han revisado con detenimiento los resultados obtenidos en la fase de prueba del test norteamericano del RDA (www.loc.gov/ catdir/cpso/RDAtest/rdatest.html), y lo mismo los otros tests que han surgido de manera local. De igual forma se exploran ahora las distintas utilerías bibliográficas con fines de capacitación y entrenamiento del catalogador, las cuales incluyen webcasts, webinarios, podcast, así como manuales de buenas prácticas. Tales equipos observan los cambios en los registros en función de las indicaciones de RDA siempre con el firme propósito de familiarizarse con éstos. Así, dependiendo de la situación administrativa de cada biblioteca, se podrá contar con el acceso a la utilería bibliográfica conocida como RDA Toolkit, la cual ofrece diversas formas para emplear el estándar e instruye de manera efectiva en las maneras de incorporar los nuevos lineamientos al trabajo cotidiano.

Tres son las ventajas que proporcionan los lineamientos RDA. Está por demás aclarar que, como todo estándar, su función primordial es auxiliar a los usuarios, de ahí que la primera ventaja responda a las necesidades de éstos, para luego suministrar las instrucciones e indicaciones prácticas para crear los registros y datos que permitan identificar las tareas del propio usuario. También sucede que, al establecer un diálogo con otras comunidades de metadatos, estos lineamientos precisen de una variedad de opciones que puedan aplicarse a todo tipo de recursos.

La segunda ventaja es para las instituciones, sean éstas bibliotecas, museos, archivos o instituciones similares. Con ayuda de los descubridores de recursos, tanto el usuario como las instituciones quedan satisfechos al experimentar nuevas for8 mas de navegación y despliegue de los datos bibliográficos. De 
ahí que el esquema de los lineamientos deba orientarse hacia la búsqueda de ventajas en los escenarios futuros de captura, almacenamiento, recuperación y despliegue de los datos, y hacia la operación efectiva de éstos en el entorno de la Web, sin dejar de lado la aparición de las nuevas tecnologías que se están orientando hacia la captura y el reúso automático de los datos.

La tercera ventaja es para los catalogadores y creadores de metadatos. Como es un conjunto de lineamientos, la RDA está provista de una estructura teórica soportada en los modelos conceptuales de los Requerimientos Funcionales, los cuales le dan solidez y guía al catalogador para que emita su juicio con el fin de decidir cuál será el dato que ayudará al usuario a completar su tarea de identificar o encontrar. Esto también permite que los catalogadores posicionen su trabajo de manera relevante para este siglo XXI y, como se ha comentado en variadas ocasiones, que los lineamientos RDA representen el cambio más significativo al permitir que se abran las puertas de manera gradual hacia una transformación de los datos y hacia la práctica de una catalogación más sencilla.

Si se está interesado en implementar los lineamientos RDA, deberá entenderse que éste es un proceso que se inicia con la transición de las Reglas de Catalogación Angloamericanas Revisadas, segunda edición, hacia tales lineamientos; y que por tanto será necesario cubrir y cumplir con nuevas disposiciones, con las que el catalogador será el más beneficiado porque estará comenzando a trabajar con la nueva lógica y consistencia que permite el estándar. Pero los usuarios observarán los beneficios de esto sólo en el momento en que sus necesidades sean el centro de su atención.

Tiempo, presupuesto y capacitación habrán de ser los componentes esenciales si es que se aspira a implementar los lineamientos RDA en cualquier institución interesada en organizar información. La fecha que se decida para realizar el cambio dependerá de la situación que guarde su sistema bibliotecario con relación a las actualizaciones indicadas en el formato MARC; será su proveedor de registros MARC quien le indicará las modificaciones hechas con base en RDA.

En su proyecto presupuestal deberá considerar la adquisición de la utilería $R D A$ Toolkit, ya que sin ésta será difícil mantenerse actualizado en las distintas novedades y cambios 
internos del estándar. Debe recordarse que es un recurso continuable que demanda una suscripción en línea. Es de vital importancia la capacitación y educación continua del personal, así como considerar el impacto que habrá sobre la productividad durante el periodo de implementación.

La capacitación formal y la educación continua tendrán que estar presentes antes y durante la ejecución del plan de implementación, por lo que deberá inscribir a su equipo de catalogación en los diversos programas formales que se impartan en instituciones acreditadas para tal fin y establecer los escenarios posibles para su cumplimiento. También cabe recordar que deberá prepararse la documentación local, así como cambiar los hábitos de los catalogadores, ya que es transcendental recordar que una vez iniciado el proceso de cambio no habrá vuelta.

Si los catalogadores no cambian sus hábitos de memorizar las reglas y depender de su experiencia, será difícil que apliquen las nuevas instrucciones del estándar, ya que éstas requieren de una consulta frecuente. RDA incluye una gran cantidad de instrucciones que remiten a la decisión de la agencia catalogadora y, consecuentemente, estimula la elaboración de políticas locales para cada caso que se tenga a la vista. Lo anterior le da validez a los tres tipos de descripciones indicadas en el estándar: descripción completa, descripción analítica y descripción jerárquica. Por tanto el catalogador necesita cambiar su postura, de lo contrario será reemplazado por el creador de metadatos.

Nos resta mencionar una estrategia para completar la implementación del RDA, a saber, la estructuración semántica de los datos que se alcanza con él. Esto permitirá que cada elemento ingrese a un espacio denominado "datos vinculados", consistente en un método estandarizado por medio del cual el contenido y las diferentes funciones de recursos se ordenan con el fin de intercambiar los datos que serán colocados en la Web.

Lo que se busca con la Descripción y Acceso es que los datos respondan a tareas administrativas como las relativas a compartir y comercializar la información dentro y fuera de la biblioteca. Con base en los requerimientos establecidos por la Web y la creación de vocabularios simples, lo que se quiere lograr es estar lo más cerca posible a un identificador único. 
En resumen, es importante reconocer que el proceso de implementación de las RDA está ya iniciando. Hay demasiada incertidumbre acerca de lo que está por venir. Un gran número de instituciones están en la fase de limpieza y ajuste de su base de datos para poder ingresar al entorno de la Web Semántica. El Formato MARC está cambiando hacia un MARCXML u otras opciones más accesibles como SCHEMA o BIBFRAME que permitirán la extracción de datos de una forma sencilla. Por éstas y muchas razones más, cualquier acción que se tome para la implementación necesariamente deberá pasar por una nueva curva de aprendizaje. Y usted ¿ya comenzó su implementación del nuevo estándar? 